\title{
A Systematic Review of Usability Challenges and Testing in Mobile Health
}

\author{
Tareq Ali Al-Saadi \\ Information Technology Directorate \\ Ministry of Science and Technology, Baghdad, Iraq \\ tareq.rabeea@gmail.com \\ Tamer Mohammed Aljarrah \\ School of computing, University Utara Malaysia \\ 06010 UUM Sintok, Kedah \\ Tamer_uum_jarrah@yahoo.com \\ Anahed Mudheher Alhashemi \\ Information Technology Directorate \\ Ministry of Science and Technology, Baghdad, Iraq \\ anaheedfareed@gmail.com
}

Azham Hussain

School of computing, University Utara Malaysia

06010 UUM Sintok, Kedah.

azham.h@uum.edu.my

DOI: 10.5296/ijafr.v5i2.8004 URL: http://dx.doi.org/10.5296/ ijafr.v5i2.8004

\begin{abstract}
Nowadays, the combining of advanced mobile communications and mobile account now in portable devices named "smart phones" has becomes more great uses. Among of these include health care professionals. Few studies in the challenge, blurred reality challenge facing the patient and developer alike in the usability of mobile health. Therefore, this paper
\end{abstract}




\section{Mll Macrothink}

International Journal of Accounting and Financial Reporting ISSN 2162-3082 2015, Vol. 5, No. 2

aims to analyze the usability challenges in mobile health and usability testing. The systematic review was using for collecting the prior studies that relation with our study. This study concentrates on the three digital libraries Google scholar, ACM and IEEE, as well as, the researcher selected the studies between 2007 and 2015. The results from this systematic were selected 11 studies of 106 based on the inclusions criteria. In more details, the usability challenges found that $27 \%$ offered User Interface, $22 \%$ tasks and screen size, $16 \%$ insert media and $13 \%$ network. On the other hand, usability use found that, $46 \%$ of the selected studies the usability use of formal type of $45 \%$ informal and $9 \%$ mixed formal and informal. Sum up, the use of smart phones is getting more on health care and day out. Medical applications make smart phones useful tools in the practice of evidence-based medicine at the point of care, in addition to its use in mobile clinical communications. This study will making a contribution to the researchers to extract over the impact of the challenges on usability testing and the types of usability in mobile health.

Keywords: Usability Challenges, Mobile Health, Smartphone, Systematic Literature Review

\section{Introduction}

This is a systematic literature review (SLR) to simplify the understanding of current developments in a field. Al-Ismail and Sajeev (Al-Ismail \& Sajeev, 2014) is an example of the SLR for classifying usability dimensions of mobile health application. Another example is the SLR by Zapata and Toval (2015) to consider which usability evaluation methods have been used for m-health application usability assessment and their relevance to the m-health application development process. The International Standards Organization, defined usability as "the extent to which a product can be used by specified users to achieve specified goals with effectiveness, efficiency and satisfaction in a specified context of use" (DIN, 1998).

Furthermore, Compared to early mobile phones, today's smartphones and tablet PCs offer a significantly wider range of functionality. Mobile applications (apps) are progressively utilized in handling various tasks in daily life. Presently, more than 900,000 apps are available in the Apple App Store (operating system: IOS, developer: Apple) and more than 700,000 apps in the Google Play Store (operating system: Android, developer: Google) (Apple, 2013). The number of health-related apps increased to 31,000 in (2013).

As well as applications that targets the sick and elderly users. It is useful for tasks that are as simple as possible .Order data entry overly bothered the user to grasp the content information from the interface of human memory work has repeatedly to switch between the input data and to understand the meaning. This becomes particularly challenging as a cover for virtual keyboard large parts of the screen. Work pattern sequences to complete the tasks. To design the interface consistent, when understand of how one screen work this help the users to understand how to monitor other acts of whether the tasks track the progress of a similar work (Xu, Ding, Huang, \& Chen, 2014).

Therefore, it is safe to say that usability defines the relation between product and its user (Amelung, Ohl, Schade, \& Wagner, 2010). From an engineering point of view, usability reduces the difficulty of the interface so users can focus on their tasks rather than focusing on 


\section{MInstitute Macrothink $_{\text {Int }}$}

International Journal of Accounting and Financial Reporting

ISSN 2162-3082

the product. Searching what the usability challenges are for accessing mobile health application from mobile devices and what are the subjects and materials required for usability testing of mobile m-health application.

\section{Systematic Review}

In this study, the systematic review was conducted based on the parameters by Kitchenham and Charters (2007). For this situation, the proposed exercises to be achieved so as to encourage the procedure of the methodical survey are: the elaboration of research questions, search strategy, the selection of primary studies, the extraction of data, and the implementation of a synthesis strategy (i.e. results analysis).

\section{Research Question(s)}

Specifying the research questions is the most important part of any systematic review. The review questions drive the entire systematic review methodology:

- The search process must identify primary studies that address the research questions.

- The data extraction process must extract the data items needed to answer the questions.

- The data analysis process must synthesize the data in such a way that the questions can be answered. The most important activity during planning is to formulate the research question(s) (Kitchenham \& Charters, 2007). Therefore, in this paper the research questions are:

RQ1: What are the challenges that simplify the use of mobile health?

RQ2: What are the themes and materials required for health mobile usability testing?

The rest of the paper is organized as follows. In the next section, the research explains a method. In Section II, identifying and classifying the challenges of mobile health usability. In Section III, exploring the subjects required and materials utilized in usability tests. In Section IV, identifying some of the limitations of this research and finally have given the conclusion.

\section{Research Method}

To undertake a SLR, Kitchenham and Chatters (2007) followed the methodology illustrated. As well as, identified the keywords to confirm every related mobile health app was detected. Hence, selected English keywords, directly related to m-health. Consequently, a protocol for literature search was formulated around our research questions. The protocol defined the choice of search engines, the search terms, and exclusion and inclusion criteria for the selection of research papers as illustrated in (Section A).

The selected papers were then evaluated by a number of quality criteria as described in Table I.

\section{Search Strategy}

To conduct SLR, followed methodology is clear from Kitchenham. Consequently, the protocol has been drafted to search the literature questions about our research. Definitions chosen are search engines protocol, search terms, and exclusion and inclusion criteria for the selection of research papers as described in (Section A). Then were evaluated and selected papers by a number of quality standards.

\section{Search}




\section{Macrothink \\ International Journal of Accounting and Financial Reporting \\ ISSN 2162-3082 2015, Vol. 5, No. 2}

\section{The search engines that used:}

Google Scholar: http://scholar.google.com.au.

Digital Library ACM: http://dl.acm.org.

Do Digital Library IEEE: http://ieeexplore.ieee.org.

Context criterion the search terms are appears on article's title, and the publication year is between 2007 and 2015, as shown in Figure 1.

C1-(Mobile AND Usability) AND (Health OR Healthcare OR Clinical OR Clinic).

C2- (Mobile AND Usability AND Challenges).

C3- (Mobile OR Smartphone OR M) AND (Health OR Healthcare OR Clinical OR Clinic) AND (Usability OR Challenges).

Consequently that the whole string used in our search was: $\mathrm{C} 1+\mathrm{C} 2+\mathrm{C} 3$.

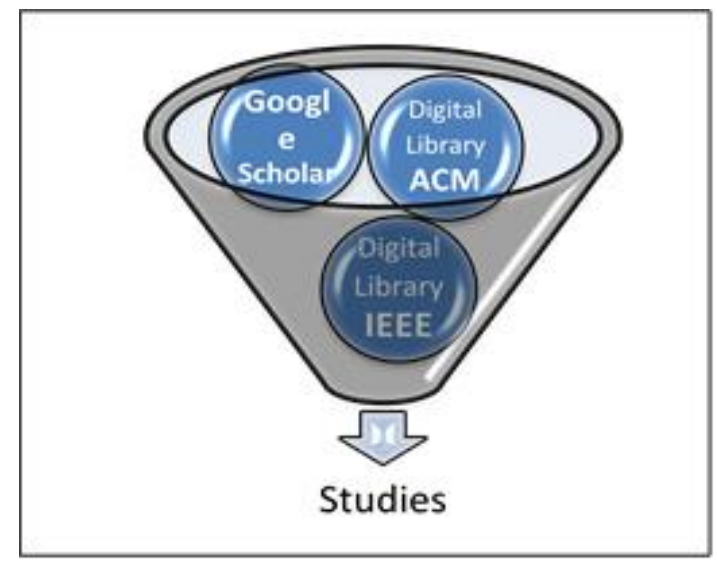

Figure 1. Search studies.

\section{Study Selection}

The published research was chose to take into account in 2007 SLR. In spite of the presence of mobile devices such as personal digital assistants (PDA), in June 2007, set to release iPhone up to a large extent a new era of smart phones, which are suitable for access to the Internet. Therefore, the possibility through the use of mobile the Internet has become a source of concern research significantly with the emergence of smart phones in 2007. The search terms lead to a (11) studies, as illustrates in Table I.

Number of papers from initial search

\begin{tabular}{|l|l|l|l|}
\hline Database & $\begin{array}{l}\text { Found } \\
\text { Articles }\end{array}$ & $\begin{array}{l}\text { Duplicate } \\
\text { Articles }\end{array}$ & $\begin{array}{l}\text { Selected } \\
\text { Articles }\end{array}$ \\
\hline Google Scholar & $\mathbf{7 3}$ & $\mathbf{2 0}$ & $\mathbf{6}$ \\
\hline $\begin{array}{l}\text { ACM Digital } \\
\text { Library }\end{array}$ & $\mathbf{1 1}$ & $\mathbf{4}$ & $\mathbf{3}$ \\
\hline
\end{tabular}




\begin{tabular}{|l|l|l|l|}
\hline $\begin{array}{l}\text { IEEE Digital } \\
\text { Library }\end{array}$ & $\mathbf{2 2}$ & $\mathbf{5}$ & $\mathbf{2}$ \\
\hline Total & $\mathbf{1 0 6}$ & $\mathbf{2 9}$ & $\mathbf{1 1}$ \\
\hline
\end{tabular}

\section{Quality Assessment}

The inclusion criteria were applied for each paper's quality,

Results have been trimmed to reduce the duplicate papers of different digital libraries. Moreover, the inclusion criteria were applied as follows:

- The paper is a preliminary study on the topic of usability on the mobile health.

- The paper is written in English and peer review.

- The paper published in or after 2007.

Applied the inclusion criteria for the quality of each sheet in:

- [Q1] Do you remember the paper challenges facing the end-user on the possibility of the use of the application mobile health?

- [Q2] Does the paper and clear way to usability testing?

They have completed a pilot study of the evaluation process by both authors to ensure the search terms of our quality assessment standards achieved. Has been granted all the paper on the basis of the degree of personal assessment of how well answered all of the questions.

- Being very well (1).

- Partly means (0.5).

- Does not mean at all (0).

\section{Results}

The got results were ordered in view of the research questions, their conceivable answers, the amount of studies and the percentage of studies that answer each one of the research questions compared to the total number of studies. This classification is shown in Table II (the percentage column in the table shows the percentage of studies that answer the research question compared to the total amount of studies). The following subsections will exhibit the itemized results for each research question.

Number of papers from initial search

\begin{tabular}{|l|l|l|l|l|l|}
\hline \multirow{2}{*}{ Study ID } & \multirow{2}{*}{ Authors and citation } & \multirow{2}{*}{ year } & \multicolumn{3}{|c|}{ Quality Score } \\
\cline { 5 - 7 } & & & Q1 & Q2 & Total \\
\hline S1[1] & Arsand et Al. & 2007 & 1 & 1 & 2 \\
\hline S2[2] & Kumar et Al. & 2013 & 1 & 1 & 2 \\
\hline
\end{tabular}




\begin{tabular}{|l|l|l|l|l|l|}
\hline S3[3] & Ahmad et Al. & 2008 & 0.5 & 1 & 1.5 \\
\hline S4[4] & Preuveneers and Berbers & 2008 & 0.5 & 1 & 1.5 \\
\hline S5[5] & Bardram et Al. & 2013 & 1 & 1 & 2 \\
\hline S6[6] & Brown et Al. & 2013 & 1 & 1 & 2 \\
\hline S7[7] & Gupta and Saurabh & 2011 & 0.5 & 1 & 1.5 \\
\hline S8[8] & Xu et Al. & 2014 & 1 & 1 & 2 \\
\hline S9[9] & Sheehan et Al. & 2012 & 1 & 1 & 2 \\
\hline S10[10] & Yeh and Fontenelle & 2012 & 1 & 1 & 2 \\
\hline S11[11] & Campbell et Al. & 2011 & 1 & 0.5 & 1.5 \\
\hline
\end{tabular}

\section{Usability challenge in m-health application}

Literature discusses a wide range of challenges in mobile health. Analysis of the literature shows that the issues discussed can be classified into two main categories: the part of the application and the challenges of the side of the device, which can be classified as shown in Figure 2. Here explained the results of each of these categories in details.

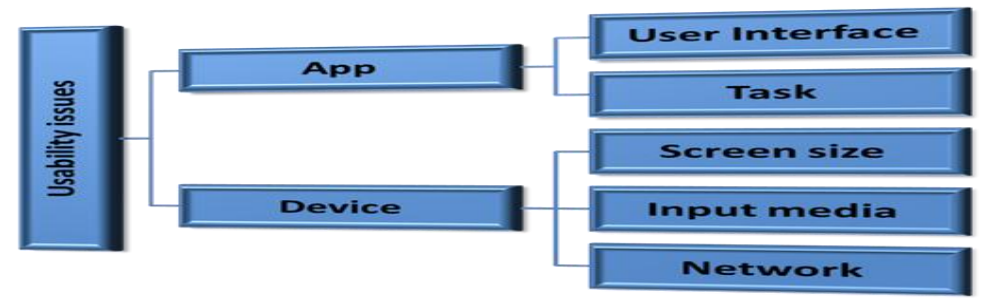

Figure2. Categories of mobile health usability issues.

In addition to that ,the user interface was the greatest percentage due to the formality, that is very complicated made which tend to be confusing to user as a result as negative response (Arsand, Varmedal, \& Hartvigsen, 2007), (Kumar, Nilsen, Pavel, \& Srivastava, 2013), (Ahmad, Komninos, \& Baillie, 2008), (Bardram et al., 2013), (Brown, Yen, Rojas, \& Schnall, 2013), (Gupta \& Gupta, 2011), (Xu et al., 2014), (Sheehan et al., 2012), (Yeh \& Fontenelle, 2012), and (Campbell, Tossell, Byrne, \& Kortum, 2011). Therefore, when the interface designed unfriendly user may cause an expected response (Kumar et al., 2013). The usability attributes of effectiveness, efficiency and satisfaction are generally measured by task completion rates, time for task completion. It was found that $22 \%$ of the studies focused on the importance of the task and clarity for users because the difficulty is important to represent a real challenge for usability. Therefore, the same proportion to the size of the screen due to required that the screen must to be large enough for the purpose of clarity, the same time the 


\section{Macrothink}

International Journal of Accounting and Financial Reporting ISSN 2162-3082 2015, Vol. 5, No. 2

device is simply to navigate and make calls (Arsand et al., 2007). It came ratio associated hardware and network ranked last in terms of the challenges of accessibility by $16 \%$ and $13 \%$, respectively, due to lack of equipment associated with the use of telecommunications and in selected studies. As shown in Table III.

Usability Issues

\begin{tabular}{|c|c|c|c|c|}
\hline Usability Issues & $\begin{array}{l}\text { Titles of } \\
\text { challenge }\end{array}$ & Study ID & $\begin{array}{c}\text { number of } \\
\text { studies }\end{array}$ & $\%$ \\
\hline \multirow[t]{2}{*}{ App } & User Interface & $\begin{array}{lll}\text { S1[1], S2[2], S6[6], } & \text { S7[7], } \\
\text { S11[11], S10[10], } & \text { S9[9], } \\
\text { S8[8], S3[3], S5[5] } & \end{array}$ & 10 & $27 \%$ \\
\hline & Tasks & $\begin{array}{l}\text { S1[1], S2[2], S6[6], S11[11], } \\
\text { S10[10], S9[9], S8[8], S3[3] }\end{array}$ & 8 & $22 \%$ \\
\hline \multirow[t]{3}{*}{ Device } & Screen size & $\begin{array}{l}\text { S1[1], S2[2], S6[6], S7[7], } \\
\text { S11[11], S9[9], S8[8], S4[4] }\end{array}$ & 8 & $22 \%$ \\
\hline & Input media & $\begin{array}{l}\mathrm{S} 1[1], \mathrm{S} 10[10], \mathrm{S} 9[9], \mathrm{S} 8[8], \\
\mathrm{S} 4[4], \mathrm{S} 5[5]\end{array}$ & 6 & $16 \%$ \\
\hline & Network & $\begin{array}{l}\mathrm{S} 1[1], \mathrm{S} 2[2], \mathrm{S} 6[6], \mathrm{S} 11[11], \\
\mathrm{S} 10[10]\end{array}$ & 5 & $13 \%$ \\
\hline
\end{tabular}

The greatest percentage between usability issues in selected studies was $27 \%$ in the user interface and $22 \%$ for screen size and task. Therefore, the lost percentage was $16 \%$ input media and $13 \%$ for networks. (See in figure 3).

\section{Usability challenge}

\section{App \& Device}

Usability Issues

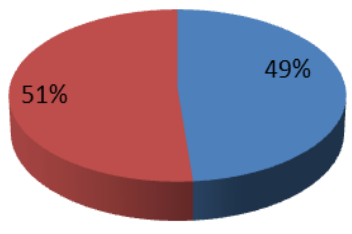

APP

Device

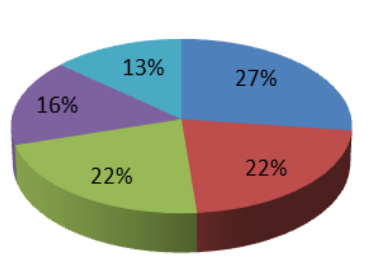

- User Interface

- Tasks

- Screen size

- Input media

Network

Figure3: Usability Issues. 
Application:Mobile application is focusing some challenges according to the SLR. These challenges include the user interface and the task.

User Interface :The user interface design has become a challenge for designers of portable health through displaying the design elements of buttons, or example text, color and icons. This can either help or prevent clients and ought to be considered carefully because of dealing with the elderly and patients (Kumar et al., 2013), (Ahmad et al., 2008), (Bardram et al., 2013), (Gupta \& Gupta, 2011), (Sheehan et al., 2012), (Yeh \& Fontenelle, 2012), and (Campbell et al., 2011).

Task: Unlike mobile users have time constraints on performing tasks because of the risk of interruptions ((Brown et al., 2013), and (Sheehan et al., 2012)) such as receiving a call while doing a tasks (Ahmad et al., 2008) (Yeh \& Fontenelle, 2012). Moreover, Campbell, Tossell, Byrne and Kortum (2011) have found significant impact of various surrounding factors on mobile health usage; they include visual motion, sound variance, luminosity (level of lighting), sound semantics (that is, meaningful sounds around the user) and proximity to other people. Furthermore, mobile users' time constraints could impact on task efficiency (Arsand et al., 2007), (Kumar et al., 2013), and (Xu et al., 2014).

Device: Device is focusing some challenges according to the SLR. These challenges include the screen size, input media and network.

Screen size: The limitation of the screen size of mobile devices is the most cited usability challenge in our study literature (Arsand et al., 2007), (Kumar et al., 2013), (Preuveneers \& Berbers, 2008), (Brown et al., 2013), (Gupta \& Gupta, 2011), (Xu et al., 2014), (Sheehan et al., 2012), and (Campbell et al., 2011). Manufacturers of smartphones seem to be conscious of this, which is evident from the way some of them have increased the size from one generation of the model to the next. For instance, Samsung's Galaxy S started with a 4" screen in 2010 and by the fourth generation S4, the screen has expanded to 5" (Al-Ismail \& Sajeev, 2014). However, since a phone's primary purpose of making phone calls requires it currently to be held next to the ear (not withstanding advances such as the use of Bluetooth technology), there is a limit on how large a phone can be made without making it an embarrassment for users to receive calls in public.

Change number of columns: Select the Columns icon from the MS Word Standard toolbar and then select "1 Column" from the selection palette.

Input media: Mobile devices have keyboard limitations (Preuveneers \& Berbers, 2008), (Bardram et al., 2013), and (Yeh \& Fontenelle, 2012) which are manifest not only in small size keys and on-screen keys but also, in superimposing several functions onto certain keys. Moreover, typing on a mobile keyboard is a difficult task because performing tasks such as shifting between lowercase, uppercase, numerals, and symbols requires a shift to a different keyboard (Xu et al., 2014). This aspect can make users frustrated while interacting with the touch screen and trying to click on small objects, such as buttons, icons, and images (Arsand et al., 2007), and (Sheehan et al., 2012).

Network: Today, mobile devices are easily connected to the Internet through several avenues involving cellular and Wi-Fi networks. However, internet connections through mobile devices are still sluggish compared to wired Ethernet connections (Kumar et al., 2013), 


\section{Ml Macrothink}

International Journal of Accounting and Financial Reporting

(Brown et al., 2013), and (Yeh \& Fontenelle, 2012). A common result of the sluggishness is user frustration, however, there can be even wider consequences for weak connectivity. For example, Campbell, Tossell, Byrne and Kortum (2011) give the case of a health study where patients' feedback to a therapist was lost when the mobile Internet connection was poor, and there was no way to retrieve it. The cost of wireless connectivity is another issue. One study showed that young mobile phone users were less prone to browse using their mobile phones compared with older users because young users could not afford the cost of Internet services (Arsand et al., 2007).

\section{Usability testing and practice in $m$-health application}

Studies selected in usability used formal, informal test or both to assess end-users comfortability using samples and often involve participants. The researcher provides further details about the participants in the usability in Table IV below.

Usability testing m-health

\begin{tabular}{|c|c|c|c|}
\hline $\begin{array}{l}\text { Article } \\
\text { no. }\end{array}$ & Title & Testing Type & Process of testing \\
\hline $\mathrm{S} 1[1]$ & $\begin{array}{l}\text { "Usability Of A } \\
\text { Mobile Self-Help } \\
\text { Tool For People } \\
\text { With Iabetes: } \\
\text { The Easy Health } \\
\text { Diary" }\end{array}$ & Formal & $\begin{array}{l}\text { in this research using of mobile } \\
\text { application tested through } 32 \text { users, all } \\
\text { results proved in general were } \\
\text { positive .So, the information } \\
\text { emphasized the importance of making } \\
\text { the tool and application extremely easy } \\
\text { to use and integrated with the everyday } \\
\text { routines of the users.. }\end{array}$ \\
\hline $\mathrm{S} 2[2]$ & $\begin{array}{l}\text { Mobile Health: } \\
\text { Revolutionizing } \\
\text { Healthcare Through } \\
\text { Trans Disciplinary } \\
\text { Research }\end{array}$ & Formal & $\begin{array}{l}\text { there have different of mobile } \\
\text { application for users such as lens-free } \\
\text { computational microscopy and } \\
\text { tomography } 4 \text { running on a smartphone } \\
\text { that can algorithmically overcome } \\
\text { optical constraints to provide } \\
\text { high-resolution 3D imaging of } \\
\text { biological samples with a wide field of } \\
\text { view and a large depth of field. These } \\
\text { methods have been shown to assay } \\
\text { blood samples for malaria and radio } \\
\text { frequency (RF) imaging, which is an } \\
\text { attractive option for smartphones as they } \\
\text { already have several built-in radio } \\
\text { transmitters and receivers. }\end{array}$ \\
\hline S6[6] & $\begin{array}{l}\text { Assessment Of The } \\
\text { Health It Usability }\end{array}$ & Formal & $\begin{array}{l}\text { the small screens with low resolution, } \\
\text { no keyboard or mouse, slow operating }\end{array}$ \\
\hline
\end{tabular}




\begin{tabular}{|c|c|c|c|}
\hline & $\begin{array}{l}\text { Evaluation Model } \\
\text { (Health-Ituem) For } \\
\text { Evaluating Mobile } \\
\text { Health (M-Health) } \\
\text { Technology }\end{array}$ & & $\begin{array}{l}\text { system and variation in connectivity are } \\
\text { unique challenges produced by testing } \\
\text { for m-Health. Adjust structures and } \\
\text { improve are important for m-Health } \\
\text { techniques while they vary of usability } \\
\text { issues from the other technologies in } \\
\text { web-based. Rapid advancing in } \\
\text { technology. While Synchronous } \\
\text { challenge for improving m-Health } \\
\text { technology. }\end{array}$ \\
\hline S7[7] & $\begin{array}{l}\text { Mobile Interface } \\
\text { Design: A } \\
\text { Comparative Study } \\
\text { On Challenges \& } \\
\text { Usability Strategies } \\
\text { Among Generations }\end{array}$ & Informal & $\begin{array}{l}\text { testing of mobile application in this } \\
\text { research by users provide them a facility } \\
\text { to switch between different modes } \\
\text { through suitable of mobile screen and } \\
\text { smart phones and provide them with a } \\
\text { clear information on screen and Clear } \\
\text { organization of information and use } \\
\text { simple symbols with few colors and } \\
\text { details. }\end{array}$ \\
\hline $\mathrm{S} 5[5]$ & $\begin{array}{l}\text { Designing Mobile } \\
\text { Health Technology } \\
\text { For Bipolar } \\
\text { Disorder: A Field } \\
\text { Trial Of The } \\
\text { Monarca System }\end{array}$ & Informal & $\begin{array}{l}\text { the users in this study using the } \\
\text { application of MONRCA in their } \\
\text { mobile, they were very clear with this } \\
\text { application a suitable with it. }\end{array}$ \\
\hline S10[10] & $\begin{array}{lr}\text { Usability } & \text { Study Of } \\
\text { A Mobile } & \text { Website: } \\
\text { The } & \text { Health } \\
\text { Sciences } & \text { Library, } \\
\text { University } & \text { Of } \\
\text { Olorado } & \\
\text { Anschutz } & \text { Medical } \\
\text { Campus, } & \\
\text { Experience }\end{array}$ & $\begin{array}{l}\text { Formal \& } \\
\text { Informal }\end{array}$ & $\begin{array}{l}\text { Because of the small size of mobile } \\
\text { screen and mobility of smart phones, the } \\
\text { usability testing of desktop application } \\
\text { that used by old ways were questionable } \\
\text { while applied to mobile applications. } \\
\text { According to the existing literature, } \\
\text { Zheng and Adipat suggested that either a } \\
\text { laboratory experiment or field study } \\
\text { should be considered depending on the } \\
\text { objectives of the study and attributes of } \\
\text { the product. }\end{array}$ \\
\hline S9[9] & $\begin{array}{lr}\text { A Comparison Of } \\
\text { Usability } & \text { Factors } \\
\text { Of Four } & \text { Mobile } \\
\text { Devices } & \text { For } \\
\text { Accessing } & \\
\text { Healthcare } & \end{array}$ & Formal & $\begin{array}{l}\text { using comparison between two the } \\
\text { differente mobile applications by users } \\
\text { which were used for diet tracking and } \\
\text { found statistically significant effect on } \\
\text { tasks steps, task time and number of }\end{array}$ \\
\hline
\end{tabular}




\begin{tabular}{|c|c|c|c|}
\hline & $\begin{array}{ll}\text { Information } & \text { By } \\
\text { Adolescents } & \end{array}$ & & errors. \\
\hline S8[8] & $\begin{array}{l}\text { A Pilot Study Of An } \\
\text { Inspection } \\
\text { Framework For } \\
\text { Automated } \\
\text { Usability Guideline } \\
\text { Reviews Of Mobile } \\
\text { Health Applications }\end{array}$ & Formal & $\begin{array}{l}\text { there are several studies on accessibility } \\
\text { and usability testing of mobile devices } \\
\text { in the health domain [20] [21].the } \\
\text { majority of mobile device usability } \\
\text { focused on personal digital assistant } \\
\text { PDAs and applications on mobile } \\
\text { devices not supporting multi touch } \\
\text { interactions. }\end{array}$ \\
\hline S3[3] & $\begin{array}{lr}\text { Future } & \text { Mobile } \\
\text { Health } & \text { Systems: } \\
\text { Designing } & \text { Personal } \\
\text { Mobile } & \\
\text { Applications } & \text { To } \\
\text { Assist } & \text { Self } \\
\text { Diagnosis } & \end{array}$ & Informal & $\begin{array}{l}\text { Our usage trial of the mobile application } \\
\text { design was limited in this research by } \\
\text { using a questionnaire for users, the } \\
\text { result was indicated to ageing users } \\
\text { suffering from presbyopia. So, testing } \\
\text { efficacy of the application with other } \\
\text { user groups that require specific needs } \\
\text { such as the third age (60+), or people at } \\
\text { risk that come from a younger } \\
\text { generation. }\end{array}$ \\
\hline S4[4] & $\begin{array}{lr}\text { Mobile } & \text { Phones } \\
\text { Assisting } & \text { With } \\
\text { Health Self-Care: A } \\
\text { Diabetes } & \text { Case } \\
\text { Study } & \end{array}$ & Informal & $\begin{array}{l}\text { testing of mobile application by } \\
\text { interview with users about their using } \\
\text { for application, some of them using the } \\
\text { mobile application per day for main } \\
\text { purpose.So, users differs with } \\
\text { percentage level of using mobile } \\
\text { application. }\end{array}$ \\
\hline S11[11] & $\begin{array}{lr}\text { Voting On A } \\
\text { Smartphone: } \\
\text { Evaluating } & \text { The } \\
\text { Usability Of An } \\
\text { Optimized } & \text { Voting } \\
\text { System } & \text { For } \\
\text { Handheld } & \text { Mobile } \\
\text { Devices } & \end{array}$ & Informal & $\begin{array}{l}\text { by testing of mobile application noted } \\
\text { though many users to avoid different } \\
\text { type of font and size, and avoid of } \\
\text { abbreviation and high bright of screen } \\
\text { colors in mobile applications. }\end{array}$ \\
\hline
\end{tabular}

This figure shows the relative size of usability testing type from 2007 to 2015 . the ccomparison is made between the percentage; as can be seen the largest percentage is formal testing with $46 . \%$ of the usability testing type. This is followed by informal usability testing type with $45 . \%$. lastly, the usability testing with the smallest percentage is 


\section{Al Macrothink}

International Journal of Accounting and Financial Reporting

ISSN 2162-3082 2015, Vol. 5, No. 2

the combination of formal and informal whisch has $9 \%$ only. However, some researcher prefered the formal testing type according to (Arsand et al., 2007), (Kumar et al., 2013), (Brown et al., 2013), (Xu et al., 2014), and (Sheehan et al., 2012). On other hand, some of authors focused on informal testing types (Ahmad et al., 2008), (Preuveneers \& Berbers, 2008), (Bardram et al., 2013), (Gupta \& Gupta, 2011), and (Campbell et al., 2011). Nonetheless, a few scholars use the mixed type of testing (Yeh \& Fontenelle, 2012). instance where formal testing were used according to specific tasks is diabetes (Arsand et al., 2007) in which mobile application was used by many in side lab to get a positive result. Forthmore, there is an example on informal usability testing of mobile applicaion in Assist Self Diagnosis (Ahmad et al., 2008). Using the mobile testing in laboratory and testing questionnaire type to test the application by users (Yeh \& Fontenelle, 2012). (See Fig 4).

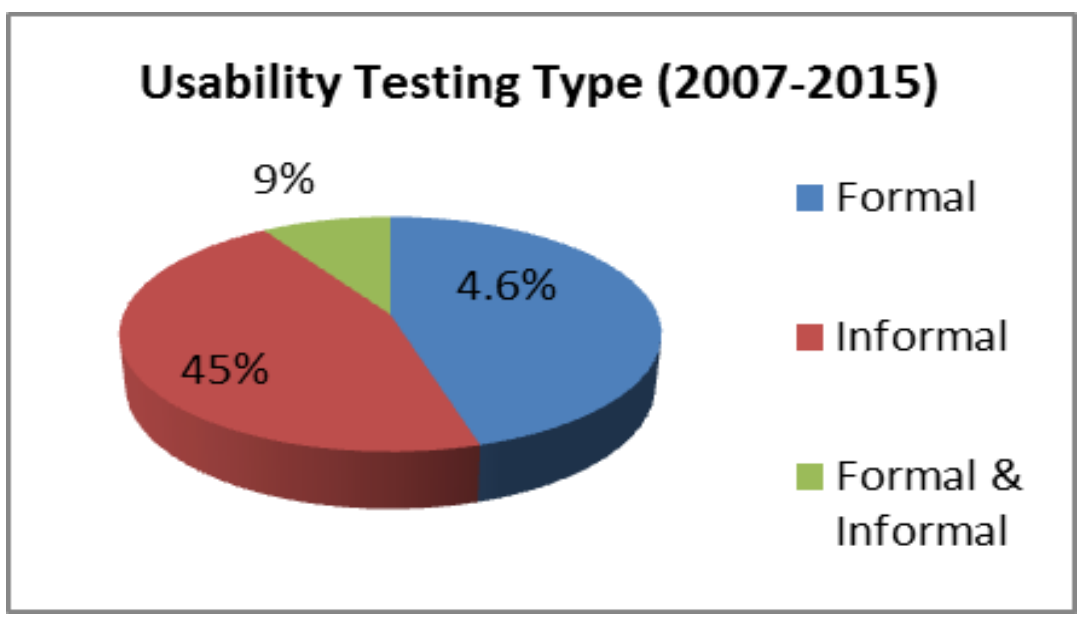

Figure4: usability Testing Type.

\section{Limitations}

As in any research, this SLR has several limitations. The research period from 2007 to 2015 which implies that papers published outside the period are excluded. This paper has not covered feature phones and personal digital assistants (PDAs) as issues identified for web access are completely different compared with smartphones with screen touch capabilities. Even though, SLR provides a deep understanding of the field, a relative studies may not be discovered and included. In future, more comprehensive SLR on mobile health application usability will be conducted in various disciplines such as mobile health usability in different sector of health.

\section{Discussion and Conclusion}

A systematic literature review is often used to methodically identify the issues reported in the literature and explains the current usability testing practices employed in mobile health application. Also, it employed the same method solve the question of research.

In addition to above, the present systematic review of the application of usability methods in 
$\mathrm{m}$-health was performed through the elaboration of a predefined protocol review that allowed us to identify and select our primary and secondary studies. Researchers discovered 106 studies, from which 11 studies were chosen. The challenges classified into application-side and device-side issues. Even though, authors found more issues on the device-side (for example, device heterogeneity, device and application capabilities) than on the application-side (for example, software-development support), this does not mean that the problem should be left to the hardware manufacturers or software providers to solve. Instead, the challenge is for application of m-health designers to take the application-side issues into account and produce application optimized to make them work irrespective of the limitations of the device.

\section{References}

Ahmad, D., Komninos, A., \& Baillie, L. (2008). Future mobile health systems: designing personal mobile applications to assist self diagnosis. In Proceedings of the 22nd British HCI Group Annual Conference on People and Computers: Culture, Creativity, Interaction-Volume 2 (pp. 39-42).

Al-Ismail, M., \& Sajeev, A. S. M. (2014). Usability Challenges in Smartphone Web Access: A Systematic Literature Review. In Service Science and Knowledge Innovation (pp. 459-470). Springer.

Amelung, H., Ohl, C., Schade, G., \& Wagner, S. (2010). Mobile Usability. Mobile Web, 2, $57-69$.

Apple: 900,000 apps in the App Store, 375,000 iPad-optimized, 28 million copies of Mountain Lion sold | The Verge. (2013). Retrieved April 4, 2015, from http://www.theverge.com/2013/6/10/4412918/apple-stats-update-wwdc-2013

Arsand, E., Varmedal, R., \& Hartvigsen, G. (2007). Usability of a mobile self-help tool for people with diabetes: the easy health diary. In Automation Science and Engineering, 2007. CASE 2007. IEEE International Conference on (pp. 863-868).

Bardram, J. E., Frost, M., Szántó, K., Faurholt-Jepsen, M., Vinberg, M., \& Kessing, L. V. (2013). Designing mobile health technology for bipolar disorder: a field trial of the monarca system. In Proceedings of the SIGCHI Conference on Human Factors in Computing Systems (pp. 2627-2636).

Brown, W., Yen, P.-Y., Rojas, M., \& Schnall, R. (2013). Assessment of the Health IT Usability Evaluation Model (Health-ITUEM) for evaluating mobile health (mHealth) technology. Journal of Biomedical Informatics, 46(6), 1080-1087.

Campbell, B. A., Tossell, C. C., Byrne, M. D., \& Kortum, P. (2011). Voting on a Smartphone Evaluating the Usability of an Optimized Voting System for Handheld Mobile Devices. In Proceedings of the Human Factors and Ergonomics Society Annual Meeting (Vol. 55, pp. 1100-1104).

DIN, E. (1998). 9241-11. Ergonomic requirements for office work with visual display terminals (VDTs)--Part 11: Guidance on usability. International Organization for 


\section{Al Macrothink}

International Journal of Accounting and Financial Reporting

ISSN 2162-3082 2015, Vol. 5, No. 2

Standardization.

Gupta, R., \& Gupta, S. (2011). Mobile Interface Design: A comparative Study on Challenges \& Usability Strategies Among Generations.

Kitchenham, B., \& Charters, S. (2007). Guidelines for performing systematic literature reviews in software engineering. URL Http://www. Dur. Ac. uk/ebse/resources/Systematic-Reviews-5-8. Pdf.

Kumar, S., Nilsen, W., Pavel, M., \& Srivastava, M. (2013). Mobile health: revolutionizing healthcare through transdisciplinary research. Computer, (1), 28-35.

Mobile Health Care Apps Growing Fast in Number | mHealthWatch. (2013). Retrieved April 4 , 2015 , from http://mhealthwatch.com/mobile-health-care-apps-growing-fast-in-number-20052/

Preuveneers, D., \& Berbers, Y. (2008). Mobile phones assisting with health self-care: a diabetes case study. In Proceedings of the 10th international conference on Human computer interaction with mobile devices and services (pp. 177-186).

Sheehan, B., Lee, Y., Rodriguez, M., Tiase, V., Schnall, R., \& others. (2012). A comparison of usability factors of four mobile devices for accessing healthcare information by adolescents. Appl Clin Inform, 3(4), 356-366.

Xu, J., Ding, X., Huang, K., \& Chen, G. (2014). A Pilot Study of an Inspection Framework for Automated Usability Guideline Reviews of Mobile Health Applications. In Proceedings of the Wireless Health 2014 on National Institutes of Health (pp. 1-8).

Yeh, S.-T., \& Fontenelle, C. (2012). Usability study of a mobile website: The health sciences library, University of Colorado Anschutz medical campus, experience. Journal of the Medical Library Association: JMLA, 100(1), 64.

Zapata, B. C., Fernández-Alemán, J. L., Idri, A., \& Toval, A. (2015). Empirical studies on usability of mHealth apps: A systematic literature review. Journal of Medical Systems, 39(2), $1-19$. 